\title{
Time from first presentation in primary care to treatment of symptomatic colorectal cancer: effect on disease stage and survival
}

\author{
P Murchie ${ }^{*}{ }^{1}$, E A Raja ${ }^{1}$, D H Brewster ${ }^{2}$, N C Campbell ${ }^{1}$, L D Ritchie ${ }^{1}$, R Robertson ${ }^{3}$, L Samuel ${ }^{4}$, N Gray ${ }^{1}$ \\ and $\mathrm{A} J \mathrm{Lee}^{1}$ \\ ${ }^{1}$ Centre of Academic Primary Care, Division of Applied Health Sciences, University of Aberdeen, Aberdeen AB25 2ZD, UK; \\ ${ }^{2}$ Scottish Cancer Registry, Information Services Division of NHS National Services Scotland, Gyle Square, 1 South Gyle Crescent, \\ Edinburgh EH12 9EB, UK; ${ }^{3}$ Scottish Collaboration for Public Health Research and Policy (SCPHRP), 20 West Richmond Street, \\ Edinburgh EH8 9DX, UK and ${ }^{4}$ Department of Oncology, Aberdeen Royal Infirmary, Aberdeen, AB25 2ZN, UK
}

Background: British 5-year survival from colorectal cancer (CRC) is below the European average, but the reasons are unclear. This study explored if longer provider delays (time from presentation to treatment) were associated with more advanced stage disease at diagnosis and poorer survival.

Methods: Data on 958 people with CRC were linked with the Scottish Cancer Registry, the Scottish Death Registry and the acute hospital discharge (SMR01) dataset. Time from first presentation in primary care to first treatment, disease stage at diagnosis and survival time from date of first presentation in primary care were determined. Logistic regression and Cox survival analyses, both with a restricted cubic spline, were used to model stage and survival, respectively, following sequential adjustment of patient and tumour factors.

Results: On univariate analysis, those with $<4$ weeks from first presentation in primary care to treatment had more advanced disease at diagnosis and the poorest prognosis. Treatment delays between 4 and 34 weeks were associated with earlier stage (with the lowest odds ratio occurring at 20 weeks) and better survival (with the lowest hazard ratio occurring at 16 weeks). Provider delays beyond 34 weeks were associated with more advanced disease at diagnosis, but not increased mortality. Following adjustment for patient, tumour factors, emergency admissions and symptoms and signs, no significant relationship between provider delay and stage at diagnosis or survival from CRC was found.

Conclusions: Although allowing for a nonlinear relationship and important confounders, moderately long provider delays did not impact adversely on cancer outcomes. Delays are undesirable because they cause anxiety; this may be fuelled by government targets and health campaigns stressing the importance of very prompt cancer diagnosis. Our findings should reassure patients. They suggest that a health service's primary emphasis should be on quality and outcomes rather than on time to treatment.

There is an important, but modest, reduction in colorectal cancer (CRC) mortality after screening suggesting that for asymptomatic CRC at least early diagnosis is beneficial (Hewitson et al, 2007; Atkin et al, 2010; Tørring et al, 2011, 2012). Whether diagnostic and treatment delays really matter after CRC symptoms and signs have developed is much less certain. Despite this, the NHS is driven by the belief that short diagnostic and treatment delays are critical, with strict targets for referral, investigation and management of suspected CRC (Department of Health, 2007; The Scottish Government, 2008; Richards, 2009). Two recent meta-analyses found no association between delays and stage at diagnosis or survival in CRC (Ramos et al, 2007, 2008). Since then, several

*Correspondence: Dr P Murchie; Email: p.murchie@abdn.ac.uk

Received 11 February 2014; revised 12 May 2014; accepted 30 May 2014; published online 3 July 2014

(c) 2014 Cancer Research UK. All rights reserved 0007-0920/14 
others have failed to demonstrate that delays influence stage at diagnosis and survival in CRC (Wattercheril et al, 2008; Iversen et al, 2009; Simunovic et al, 2009; Terhaar sive Droste et al, 2010). The methodological rigour of existing studies is sub-optimal, however, paying scant attention to important patient and tumour characteristics and treating the effect of time to treatment on disease stage and survival as linear. More recent work from Denmark concludes that it is not (Tørring et al, 2011, 2012). These studies, which are strengthened by clearer definitions of the delays experienced by patients in the diagnosis and treatment of cancer, found a non-monotonic relationship between provider delay and 3-year mortality from colorectal cancer (Weller et al, 2012; Tørring et al, 2011, 2012). In the Danish study, survival was poorest among those treated most rapidly, improving briefly as time to diagnosis increased, before deteriorating again after a few weeks. This suggested that delays before diagnosis are important if an initial poor prognostic group with aggressive disease is excluded. The authors, however, had limited scope to adjust for factors associated with aggressive disease, such as tumour grade or symptoms and signs at presentation.

The present study explored whether patients with longer times between first presentation in primary care and treatment (provider delay) had more advanced stage at diagnosis and poorer survival for CRC when important confounders such as tumour grade and symptoms and signs were taken into account.

\section{MATERIALS AND METHODS}

Data were linked from four datasets. The CRUX (Comparing Rural and Urban Cancer Care) dataset, collected in 2000 and 2001, provides primary care data on people diagnosed in Northern Scotland with CRC between 1997 and 1998 (Robertson et al, 2004). Data includes details of consultations with relevant symptoms and signs before diagnosis (Scottish Intercollegiate Guideline Network (SIGN), 2003; Robertson et al, 2004). Date of first presentation in primary care was the first record of a relevant sign or symptom of CRC preceding diagnosis. Subsequently dates of first hospital referral, diagnosis, and first treatment were recorded. Patients with symptoms and signs for $>2$ years before treatment were excluded. This dataset was linked to the Scottish Cancer Registry to obtain modified Dukes' stage and tumour grade (Brewster et al, 2002; Brewster and Stockton, 2008). Further linkage was made to the General Register Office for Scotland Death Registry (for date of death, primary and secondary causes), and SMR01, an episodebased record of all discharges from Scottish hospitals (Kendrick and Clarke, 1993; Kendrick, 1997). The Scottish Cancer Registry and CRUX datasets were linked directly using the Scottish Cancer Registry ID number. The SMR01 and death records were linked using computerised probability linkage (Harley and Jones, 1996). Linkage was performed at ISD Scotland, the final dataset supplied as an SPSS (IBM SPSS Statistics for Windows, Version 20.0, IBM Corp, Armonk, NY, USA) datafile with all personal identifying information removed.

Statistical analysis. The two main outcomes were stage at diagnosis (Dukes A, B, C or D) and all cause survival from date of first presentation in primary care. Survival was measured from date of presentation rather than date of diagnosis or treatment to overcome lead-time bias. A sensitivity analysis was also conducted measuring survival from date of diagnosis or treatment and is presented as Supplementary Note 1.

The main predictor variable was defined as time from first presentation in primary care to first treatment or to definitive diagnosis as recorded in the Scottish Cancer Registry if no treatment was given. A range of potential confounders were available including tumour site, stage at diagnosis, grade of differentiation, place of presentation, specific symptoms and signs at presentation, type of admission (emergency or elective), age, gender, smoking status, Carstairs deprivation quintile and Charlson co-morbidity index (Charlson et al, 1987; Morris and Carstairs, 1991).

Data were analysed using Stata (Version 11; StataCorp, College Station, TX, USA). Provider delay (time from first presentation in primary care to treatment) was converted into weeks and treated as a continuous variable. Stage was collapsed into a binary variable (early (A or B) vs advanced (C or D)). A stringent $P$-value $\leqslant 0.01$ was used to denote statistical significance throughout the analysis. This was chosen to minimise the chance of a Type 1 error arising from multiple testing. To explore the relationship between provider delay and stage at diagnosis, logistic regression was used. An unadjusted odds ratio (OR) and 99\% confidence interval (CI) for provider delay (weeks) was calculated and three sequentially adjusted models were run. Potential confounders were those that were deemed to be clinically important and/or showed a univariate relationship with outcome at a conservative $P \leqslant 0.10$. In model 2 , age, smoking status, Carstairs deprivation quintile, Charlson co-morbidity index and place of presentation were included. Model 3 added tumour grade and type of hospital admission, while model 4 further added a range of symptoms and signs (constipation, rectal bleeding, abdominal pain, anorexia, weight loss and abdominal mass).

Cox survival analysis was used to examine the relationship between provider delay and mortality with hazard ratios (HRs) and 99\% CIs being calculated. As before, four sequential models were fitted adjusting for patient factors, tumour grade and type of hospital admission, symptoms and signs. The proportional hazard assumption is based on Schoenfeld residuals (no violations were detected in the current analyses) (Hess, 1995).

To model the nonlinear relationship between provider delay and either stage or mortality, a restricted cubic spline (RCS) procedure was adopted (Dupout, 2008). This uses multiple polynomial line segments within the range of provider delay, the boundaries of these line segments being called knots. Knots are placed at equally spaced centiles of the distribution of provider delay. In the current analyses, five knots were considered and placed at the 0th, 25th, 50th, 75th and 100th percentile points of provider delay. A spline function was assumed to be significant if the $P$-value for the model $\chi^{2}$ was $\leqslant 0.01$ and the association is assumed to be nonlinear if the spline coefficients differ significantly from each other based on the Wald test for linearity. A provider delay value of 4 weeks was used as the reference value to estimate odds of late stage disease in the logistic RCS analyses and the HR of mortality in the RCS Cox analyses. A further stratified analysis of the relationship between provider delay, stage and mortality was conducted treating colonic and rectal tumours separately (Supplementary Note 2).

\section{RESULTS}

A total of 958 patients with symptomatic CRC were included in the survival analysis. Of 958 patients, 868 had data on stage (Table 1). The median (IQR) provider delay was 17 (8-39) weeks. Over half the cohort was male (56.6\%), the mean (s.d.) age was 69.9 (10.8) years and over $75 \%$ of patients were in the three least deprived quintiles.

Stage as the outcome. In univariate logistic regression analysis, younger age, co-morbidities and higher grade tumours were significant predictors of advanced stage (Table 1).

Table 2 presents the results of the logistic RCS analyses to explore the association of provider delay on advanced stage at diagnosis. In the fully adjusted model 4 , provider delay of 40 and 60 weeks was associated with later stage disease at presentation, but 
Table 1. Univariate analysis showing the relationship between stage at diagnosis and various factors for patients with CRC

\begin{tabular}{|c|c|c|c|c|}
\hline Factor & Overall $(n=868)$ & Stage A or B $(n=443)$ & Stage $C$ or $D(n=425)$ & OR $(99 \% \mathrm{Cl})$ \\
\hline Provider delay median (IQR) weeks & $17(8,39)$ & $17(9,39)$ & $17(8,39)$ & $0.99(0.99,1.00)$ \\
\hline Age median (IQR) years & $71(64,78)$ & $73(66,79)$ & $70(62,76)$ & $0.98(0.96,0.99)$ \\
\hline \multicolumn{5}{|l|}{ Gender } \\
\hline $\begin{array}{l}\text { Male } \\
\text { Female }\end{array}$ & $\begin{array}{l}491(56.6) \\
377(43.4)\end{array}$ & $\begin{array}{l}235(53.1) \\
208(47.0)\end{array}$ & $\begin{array}{l}256(60.2) \\
169(39.8)\end{array}$ & $\begin{array}{c}1.34(0.94,1.91) \\
1.00\end{array}$ \\
\hline \multicolumn{5}{|l|}{ Smoking status } \\
\hline $\begin{array}{l}\text { Non-smoker } \\
\text { Current smoker } \\
\text { Ex-smoker } \\
\text { Not known }\end{array}$ & $\begin{array}{l}326(37.6) \\
137(15.8) \\
191(22.0) \\
214(24.7)\end{array}$ & $\begin{array}{r}177(40.0) \\
65(14.7) \\
99(22.4) \\
102(23.0)\end{array}$ & $\begin{array}{r}149(35.1) \\
72(16.9) \\
92(21.7) \\
112(26.4)\end{array}$ & $\begin{array}{c}1.00 \\
1.32(0.78,2.23) \\
1.10(0.69,1.77) \\
1.30(0.83,2.05)\end{array}$ \\
\hline \multicolumn{5}{|l|}{ Carstairs quintile } \\
\hline $\begin{array}{l}1 \text { (least deprived) } \\
2 \\
3 \\
4 \\
5 \text { (most deprived) }\end{array}$ & $\begin{array}{l}207(24.3) \\
230(27.0) \\
206(24.2) \\
149(17.5) \\
61(7.2)\end{array}$ & $\begin{array}{r}98(22.6) \\
133(30.7) \\
100(23.0) \\
69(15.9) \\
34(7.8)\end{array}$ & $\begin{array}{r}109(26.0) \\
97(23.1) \\
106(25.3) \\
80(19.1) \\
27(6.4)\end{array}$ & $\begin{array}{c}1.00 \\
0.66(0.40,1.08) \\
0.95(0.57,1.58) \\
1.04(0.60,1.82) \\
0.71(0.34,1.52)\end{array}$ \\
\hline Charlson index (median (IQR) & $1(0,2)$ & $1(0,2)$ & $1(0,2)$ & $1.14(1.05,1.24)$ \\
\hline \multicolumn{5}{|l|}{ Place of presentation } \\
\hline $\begin{array}{l}\text { GP surgery } \\
\text { GP home visit } \\
\text { GP out of hours visit } \\
\text { Other } \\
\text { Not known }\end{array}$ & $\begin{array}{c}676(77.9) \\
111(12.8) \\
33(3.8) \\
22(2.5) \\
26(3.0)\end{array}$ & $\begin{array}{r}350(79.0) \\
59(13.3) \\
12(2.7) \\
10(2.3) \\
12(2.7)\end{array}$ & $\begin{array}{c}326(76.7) \\
52(12.2) \\
21(4.9) \\
12(2.8) \\
14(3.3)\end{array}$ & $\begin{array}{c}1.00 \\
0.95(0.56,1.61) \\
1.88(0.72,4.87) \\
1.29(0.42,3.95) \\
1.25(0.45,3.52)\end{array}$ \\
\hline \multicolumn{5}{|l|}{ Tumour grade } \\
\hline $\begin{array}{l}\text { I } \\
\text { II } \\
\text { III/IV } \\
\text { Ungradeable }\end{array}$ & $\begin{array}{c}42(4.9) \\
550(64.2) \\
147(17.2) \\
118(13.8)\end{array}$ & $\begin{array}{r}36(8.2) \\
293(66.7) \\
53(12.1) \\
57(13.0)\end{array}$ & $\begin{array}{r}6(1.44) \\
257(61.5) \\
94(22.5) \\
61(14.6)\end{array}$ & $\begin{array}{c}1.00 \\
5.26(1.65,16.74) \\
10.6(3.14,36.01) \\
6.42(1.88,21.99)\end{array}$ \\
\hline \multicolumn{5}{|l|}{ Type of hospital admission } \\
\hline $\begin{array}{l}\text { Elective admission } \\
\text { Emergency admission }\end{array}$ & $\begin{array}{l}631(72.7) \\
237(27.3)\end{array}$ & $\begin{array}{l}328(74.0) \\
115(26.0)\end{array}$ & $\begin{array}{l}303(71.3) \\
122(28.7)\end{array}$ & $\begin{array}{c}1.00 \\
1.15(0.78,1.70)\end{array}$ \\
\hline \multicolumn{5}{|l|}{ Symptom } \\
\hline $\begin{array}{l}\text { Constipation } \\
\text { Rectal bleeding } \\
\text { Abdominal pain } \\
\text { Anorexia } \\
\text { Weight loss } \\
\text { Abdominal mass }\end{array}$ & $\begin{array}{c}118(13.6) \\
252(29.0) \\
251(28.9) \\
34(3.9) \\
79(9.1) \\
49(5.7)\end{array}$ & $\begin{array}{c}49(11.1) \\
140(31.6) \\
118(26.6) \\
12(2.7) \\
37(8.4) \\
29(6.6)\end{array}$ & $\begin{array}{r}69(16.2) \\
112(26.4) \\
133(31.3) \\
22(5.2) \\
42(9.9) \\
20(4.7)\end{array}$ & $\begin{array}{l}1.56(0.93,2.61) \\
0.77(0.53,1.14) \\
1.25(0.85,1.85) \\
1.96(0.76,5.03) \\
1.20(0.65,2.21) \\
0.71(0.32,1.52)\end{array}$ \\
\hline
\end{tabular}

the ORs did not reach statistical significance. In addition, older age was associated with earlier stage disease, whereas higher grade tumours and a higher Charlson co-morbidity index were independently associated with more advanced stage. The nonlinear relationship between provider delay and stage are illustrated by the spline curves shown in Figures 1 and 2. These curves plot the length of the provider delay on the $\mathrm{X}$-axis against the odds of patients having later stage disease on the $\mathrm{Y}$-axis. Figure 1 shows the spline curves for each of the four sequential models from the unadjusted model (solid line) through varying degrees of adjustment to the fully adjusted model (long dash dotted line). Overall, provider delay was significantly associated with stage in the unadjusted model $(P=0.002)$ and the $P$-value for the nonlinear association was $P=0.04$. Treatment delays between 4 and 34 weeks (with the lowest OR occurring at 20 weeks) were associated with earlier stage. Treatment delays beyond this were associated with more advanced disease at diagnosis, although the odds began to diminish again after about 1 year. Adjusting for confounders reduced the odds of advanced disease for those with short delays, but had little other impact. Figure 2 shows the fully adjusted model of provider delay on odds $(99 \% \mathrm{CI})$ of late stage disease after adjustment for patient and tumour factors, emergency admissions and symptoms and signs. The CIs were wide such that there did not appear to be a strong relationship between provider delay and stage of CRC at diagnosis after multi-adjustment. The analysis of the relationship between provider delay and stage for colonic and 
Table 2. Logistic regression model with a 4 knot restricted cubic spline for the association of provider delay on stage (4 week delay as reference)

\begin{tabular}{|c|c|c|c|c|}
\hline & Model 1 & Model 2 & Model 3 & Model 4 \\
\hline & OR $(99 \% \mathrm{Cl})$ & OR $(99 \% \mathrm{Cl})$ & OR $(99 \% \mathrm{Cl})$ & OR $(99 \% \mathrm{Cl})$ \\
\hline \multicolumn{5}{|c|}{ Provider delay (weeks) } \\
\hline $\begin{array}{l}4 \\
20 \\
40 \\
60\end{array}$ & $\begin{array}{c}1.00 \\
0.73(0.501 .07) \\
1.29(0.881 .88) \\
1.41(0.922 .17)\end{array}$ & 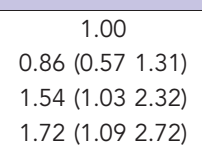 & $\begin{array}{c}1.00 \\
0.84(0.541 .32) \\
1.46(0.952 .25) \\
1.61(0.992 .60)\end{array}$ & $\begin{array}{c}1.00 \\
0.87(0.541 .39) \\
1.46(0.932 .31) \\
1.58(0.962 .61)\end{array}$ \\
\hline Age & & $0.97(0.950 .99)$ & $0.97(0.950 .99)$ & $0.97(0.950 .99)$ \\
\hline \multicolumn{5}{|l|}{ Gender } \\
\hline $\begin{array}{l}\text { Male } \\
\text { Female }\end{array}$ & & $\begin{array}{c}1.32(0.891 .95) \\
1.00 \\
\end{array}$ & $\begin{array}{c}1.30(0.871 .95) \\
1.00\end{array}$ & $\begin{array}{c}1.28(0.851 .92) \\
1.00\end{array}$ \\
\hline \multicolumn{5}{|l|}{ Smoking status } \\
\hline $\begin{array}{l}\text { Non-smoker } \\
\text { Current smoker } \\
\text { Ex-smoker } \\
\text { Not known }\end{array}$ & & $\begin{array}{c}1.00 \\
1.13(0.641 .98) \\
1.04(0.621 .72) \\
1.43(0.882 .33)\end{array}$ & $\begin{array}{c}1.00 \\
1.25(0.692 .25) \\
1.05(0.621 .78) \\
1.57(0.952 .60)\end{array}$ & $\begin{array}{c}1.00 \\
1.19(0.662 .17) \\
1.06(0.621 .81) \\
1.52(0.912 .53)\end{array}$ \\
\hline \multicolumn{5}{|c|}{ Carstairs deprivation quintile } \\
\hline $\begin{array}{l}1 \text { (least) } \\
2 \\
3 \\
4 \\
5 \text { (most) }\end{array}$ & & 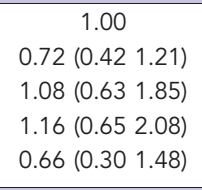 & 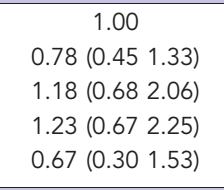 & 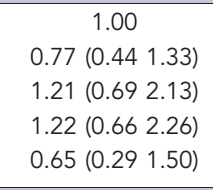 \\
\hline \multicolumn{5}{|c|}{ Place of presentation } \\
\hline $\begin{array}{l}\text { GP surgery } \\
\text { GP home visit } \\
\text { GP out of hours visit } \\
\text { Others } \\
\text { Missing } \\
\text { Charlson Index }\end{array}$ & & $\begin{array}{c}1.00 \\
1.07(0.591 .94) \\
1.85(0.675 .08) \\
1.21(0.354 .11) \\
1.18(0.403 .48) \\
1.17(1.071 .27) \\
\end{array}$ & $\begin{array}{c}1.00 \\
1.09(0.582 .03) \\
2.03(0.705 .88) \\
1.06(0.293 .81) \\
1.11(0.353 .52) \\
1.18(1.081 .30)\end{array}$ & $\begin{array}{c}1.00 \\
1.08(0.582 .04) \\
2.03(0.695 .91) \\
1.17(0.324 .28) \\
1.24(0.384 .02) \\
1.18(1.071 .30) \\
\end{array}$ \\
\hline \multicolumn{5}{|l|}{ Grade } \\
\hline $\begin{array}{l}\text { Grade I } \\
\text { Grade II } \\
\text { Grade III/IV } \\
\text { Ungradeable }\end{array}$ & & & $\begin{array}{c}1.00 \\
6.16(1.8720 .25) \\
14.29(4.0550 .42) \\
6.78(1.9024 .12)\end{array}$ & $\begin{array}{c}1.00 \\
6.16(1.8520 .46) \\
14.46(4.0751 .43) \\
7.05(1.9625 .32)\end{array}$ \\
\hline Emergency admission & & & 0.88 (0.53 1.47) & 0.82 (0.49 1.38) \\
\hline Constipation & & & & 1.54 (0.86 2.73) \\
\hline Rectal bleeding & & & & $0.84(0.521 .35)$ \\
\hline Abdominal Pain & & & & $1.16(0.731 .84)$ \\
\hline Anorexia & & & & $1.76(0.615 .06)$ \\
\hline Weight loss & & & & 1.33 (0.65 2.73) \\
\hline Abdominal Mass & & & & $0.83(0.342 .03)$ \\
\hline
\end{tabular}

rectal tumours separately lacked statistical power, but provided no real evidence of any difference between the two cancer sites (Supplementary Note 2).

Mortality as the outcome. In univariate survival analysis, older age, a higher Charlson co-morbidity index, higher grade tumours, presentation through a general practitioner home visit, emergency admission and the symptom anorexia were each associated with a significantly increased hazard of mortality (Table 3 ).
Table 4 presents the results of the sequential Cox survival analyses. In the fully adjusted model, age, male gender, a higher Charlson co-morbidity index, higher tumour grade and the symptoms and signs of anorexia and abdominal mass were each independently associated with an increased hazard of mortality. In the unadjusted model, provider delay was inversely associated with mortality $(P<0.001)$ and the association was nonlinear $(P<0.001)$. Figure 3 displays separate spline curves for each of the four survival models, illustrating the effect of sequential adjustment for potential 


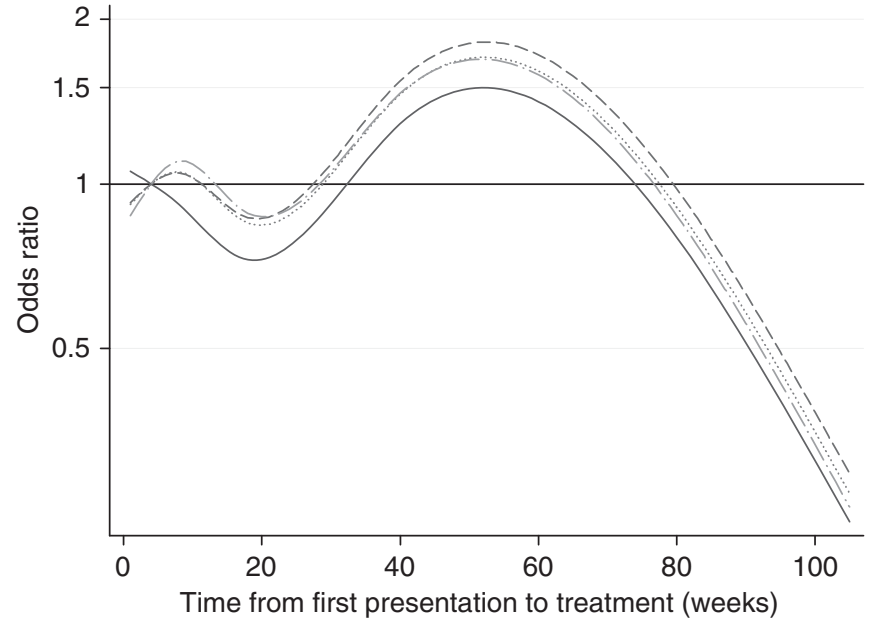

Figure 1. Spline curve of logistic regression of provider delay (weeks) on odds of having later stage $(C+D)$ disease at diagnosis. Model 1 (solid line): unadjusted model with four knots (provider delay of 4 weeks used as reference). Model 2 (dashed line): adjusted for place of presentation, patient age, patient gender, smoking status, Carstairs deprivation quintile and Charlson index. Model 3 (dotted line): further adjusted for tumour grade and type of admission. Model 4 (long dash and dotted line): further adjusted for symptoms and signs of constipation, rectal bleeding, abdominal pain, anorexia, weight loss and abdominal mass.

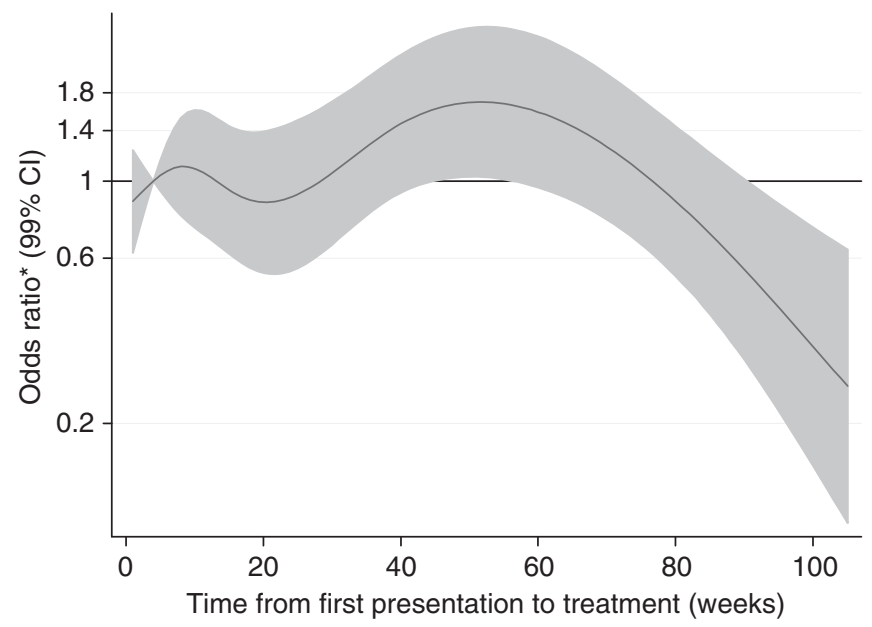

Figure 2. Spline curve of logistic regression of provider delay (weeks) on odds ratio (shaded area are $99 \% \mathrm{Cls}$ ) of having later stage $(C+D)$ disease at diagnosis after multi-adjustment for potential confounders. Reference category is 4 weeks delay. Model adjusted for age, gender, smoking status, Carstairs deprivation quintile, Charlson index, place of presentation, tumour grade, type of admission, and for symptoms and signs of constipation, rectal bleeding, abdominal pain, anorexia, weight loss and abdominal mass.

confounders. In the unadjusted model, treatment delays $<4$ weeks were associated with poor survival, but this association was no longer present after adjusting for confounders. An initial U-shaped survival curve in the unadjusted model (with lowest HR at $\sim 16$ weeks) became less pronounced with sequential adjustment. Figure 4 shows the spline curve for the fully adjusted model along with the 99\% CIs. For people with CRC, after simultaneous adjustment for patient factors, tumour factors and symptoms, longer provider delay was not significantly associated with survival from CRC. Due to smaller numbers, the analysis of the relationship between provider delay and mortality for colonic and rectal tumours separately lacked statistical power, but provided no real evidence of any difference between the two cancer sites (Supplementary Note 2).

\section{DISCUSSION}

Summary of main findings. We have confirmed that there is a nonlinear relationship between time before treatment and both disease stage and survival. Colorectal cancer patients with very short provider delays have a poor prognosis explained by their personal characteristics and features of the tumour, including grade and symptoms. These patients apart, however, we have not found that longer provider delays are associated with poorer survival. In both analyses, CIs were wide so the possibility of long provider delays having deleterious effects on stage at diagnosis and survival cannot be excluded. However, any true effect from provider delay on CRC outcome seems likely to be small in population terms, certainly when compared with patient delays which are likely to have a much greater role (Simon et al, 2010). When explored separately, there appeared to be no obvious difference in the relationship between provider delay, mortality and stage between colonic or rectal tumours.

Strengths and limitations. Some limitations of the current analyses should be acknowledged. An historical sample (patients diagnosed with symptomatic CRC between 1997 and 1998) was used predating important changes in management, and it is important to emphasise that the patterns of delays experienced by patients may be different now. For example, bowel screening will increase the proportion of people diagnosed pre-symptomatically, although fewer than 15\% of CRC cases in Scotland since 2007 were screen detected (Information and Statistics Division (ISD), 2013). Treatment has also improved since 1998, particularly more widespread adjuvant chemotherapy, and pre-operative radiotherapy in rectal cancer. Both advances, however, may even further attenuate any relationship between provider delay and outcome. It does not seem likely that there will have been important changes in the biology of CRC in that time, but the possibility should not be discounted out-of-hand. Most importantly, while our results provide reassurance, they should not engender complacency. The quality of clinical data continues to improve along with scope to link those data from primary care, secondary care and national registries. The methods reported here should be replicated using increasingly detailed and sophisticated linked clinical datasets so that knowledge on the relationship between delay and outcome continues to accumulate. This was an observational retrospective study dependent on good quality data within primary care-held medical records. For those presenting a long time before treatment, their initial symptoms and signs may have been due to other causes, which may account for falling odds of late stage disease and improving survival observed with provider delays of more than a year.

There are, however, several strengths to the analysis. This was a population-based sample, including all patients diagnosed within the study period and not limited to those treated within tertiary cancer centres. The sample was large with high levels of complete follow-up and was effectively linked to high quality routine datasets. The extent of the data enabled a detailed analysis adjusting for a greater array of potential explanatory variables than previously. Our choice of variables included in the regression model was pragmatic. Tumour stage as a predictor variable was excluded from the multivariate survival models since, if time between presentation and treatment is an important factor for survival, then its effect would be via more advanced disease stage. In contrast, tumour grade is less likely to be on the causal pathway 
Table 3. Relationship between patient and tumour factors and symptoms and signs with survival among CRC patients

\begin{tabular}{|c|c|c|c|c|}
\hline Factor & Total $(n=958)$ & Deaths ( $n=762)$ & $\mathrm{HR}$ & $99 \% \mathrm{Cl}$ \\
\hline Provider delay median (IQR) weeks & $17(8,39)$ & $17(8,39)$ & 0.99 & $0.992,0.999$ \\
\hline Age median (IQR) years & $71(64,78)$ & $74(67,79)$ & 1.04 & $1.03,1.05$ \\
\hline \multicolumn{5}{|l|}{ Gender } \\
\hline $\begin{array}{l}\text { Male } \\
\text { Female }\end{array}$ & $\begin{array}{l}540(56.4) \\
418(43.6)\end{array}$ & $\begin{array}{l}439(81.3) \\
323(77.3)\end{array}$ & $\begin{array}{l}1.18 \\
1.00\end{array}$ & $0.98,1.42$ \\
\hline \multicolumn{5}{|l|}{ Smoking status } \\
\hline $\begin{array}{l}\text { Never smoked } \\
\text { Current smoker } \\
\text { Ex-smoker } \\
\text { Not known }\end{array}$ & $\begin{array}{l}358(37.4) \\
149(15.6) \\
209(21.8) \\
242(25.3)\end{array}$ & $\begin{array}{l}270(75.4) \\
117(78.5) \\
175(83.7) \\
200(82.6)\end{array}$ & $\begin{array}{l}1.00 \\
1.14 \\
1.24 \\
1.33\end{array}$ & $\begin{array}{l}0.86,1.51 \\
0.96,1.59 \\
1.04,1.69\end{array}$ \\
\hline \multicolumn{5}{|l|}{ Carstairs deprivation quintile } \\
\hline $\begin{array}{l}1 \text { (least deprived) } \\
2 \\
3 \\
4 \\
5 \text { (most deprived) }\end{array}$ & $\begin{array}{c}227(24.1) \\
255(27.0) \\
231(24.5) \\
165(17.5) \\
65(6.9)\end{array}$ & $\begin{array}{r}167(73.6) \\
195(76.5) \\
204(88.3) \\
133(80.6) \\
51(78.5)\end{array}$ & $\begin{array}{l}1.00 \\
1.05 \\
1.43 \\
1.32 \\
1.17\end{array}$ & $\begin{array}{l}0.80,1.37 \\
1.09,1.87 \\
0.97,1.77 \\
0.77,1.76\end{array}$ \\
\hline Charlson index median (IQR) & $1(0,2)$ & $2(0,2)$ & 1.16 & $1.12,1.20$ \\
\hline \multicolumn{5}{|l|}{ Tumour grade } \\
\hline $\begin{array}{l}\text { Grade I } \\
\text { Grade II } \\
\text { Grade III/IV } \\
\text { Ungraded }\end{array}$ & $\begin{array}{c}46(4.9) \\
571(60.5) \\
158(16.7) \\
169(17.9)\end{array}$ & $\begin{array}{r}35(76.1) \\
434(76.0) \\
136(86.1) \\
145(85.8)\end{array}$ & $\begin{array}{l}1.00 \\
1.09 \\
1.72 \\
1.75\end{array}$ & $\begin{array}{l}0.69,1.71 \\
1.05,2.80 \\
1.08,2.85\end{array}$ \\
\hline \multicolumn{5}{|l|}{ Place of original presentation } \\
\hline $\begin{array}{l}\text { GP surgery } \\
\text { GP home visit } \\
\text { GP out of hours visit } \\
\text { Others } \\
\text { Missing }\end{array}$ & $\begin{array}{c}737(76.9) \\
128(13.4) \\
37(3.9) \\
25(2.6) \\
31(3.2)\end{array}$ & $\begin{array}{r}565(76.7) \\
121(94.5) \\
30(81.1) \\
21(84.0) \\
25(90.7)\end{array}$ & $\begin{array}{l}1.00 \\
1.86 \\
1.12 \\
1.39 \\
1.29\end{array}$ & $\begin{array}{l}1.43,2.41 \\
0.69,1.83 \\
0.78,2.46 \\
0.76,2.18\end{array}$ \\
\hline \multicolumn{5}{|l|}{ Type of admission } \\
\hline $\begin{array}{l}\text { No emergency admission } \\
\text { Emergency admission }\end{array}$ & $\begin{array}{l}699(73.0) \\
259(27.0)\end{array}$ & $\begin{array}{l}539(77.1) \\
223(86.1)\end{array}$ & $\begin{array}{l}1.00 \\
1.47\end{array}$ & $1.19,1.80$ \\
\hline \multicolumn{5}{|l|}{ Constipation } \\
\hline $\begin{array}{l}\text { Yes } \\
\text { No }\end{array}$ & $\begin{array}{l}133(13.9) \\
825(86.1)\end{array}$ & $\begin{array}{l}112(84.2) \\
650(78.8)\end{array}$ & $\begin{array}{l}1.19 \\
1.00\end{array}$ & $0.91,1.55$ \\
\hline \multicolumn{5}{|l|}{ Rectal bleeding } \\
\hline $\begin{array}{l}\text { Yes } \\
\text { No }\end{array}$ & $\begin{array}{l}273(28.5) \\
685(71.5)\end{array}$ & $\begin{array}{l}192(70.3) \\
570(83.2)\end{array}$ & $\begin{array}{l}0.70 \\
1.00\end{array}$ & $0.56,0.87$ \\
\hline \multicolumn{5}{|l|}{ Abdominal pain } \\
\hline $\begin{array}{l}\text { Yes } \\
\text { No }\end{array}$ & $\begin{array}{l}273(28.5) \\
685(71.5)\end{array}$ & $\begin{array}{l}224(82.1) \\
538(78.5)\end{array}$ & $\begin{array}{l}1.14 \\
1.00\end{array}$ & $0.93,1.40$ \\
\hline \multicolumn{5}{|l|}{ Anorexia } \\
\hline $\begin{array}{l}\text { Yes } \\
\text { No }\end{array}$ & $\begin{array}{c}45(4.7) \\
913(95.3)\end{array}$ & $\begin{array}{r}42(93.3) \\
720(78.9)\end{array}$ & $\begin{array}{l}1.88 \\
1.00\end{array}$ & $1.25,2.83$ \\
\hline \multicolumn{5}{|l|}{ Weight loss } \\
\hline $\begin{array}{l}\text { Yes } \\
\text { No }\end{array}$ & $\begin{array}{c}94(9.8) \\
864(90.2)\end{array}$ & $\begin{array}{r}82(87.2) \\
680(78.7)\end{array}$ & $\begin{array}{l}1.33 \\
1.00\end{array}$ & $0.98,1.79$ \\
\hline \multicolumn{5}{|l|}{ Abdominal mass } \\
\hline $\begin{array}{l}\text { Yes } \\
\text { No }\end{array}$ & $\begin{array}{c}57(6.0) \\
901(94.0)\end{array}$ & $\begin{aligned} 48(84.21) \\
714(79.3)\end{aligned}$ & $\begin{array}{l}1.43 \\
1.00\end{array}$ & $0.98,2.11$ \\
\hline
\end{tabular}


Table 4. Cox proportional hazards model to find the association between mortality and time to treatment as a continuous variable (4 week delay as reference)

\begin{tabular}{|c|c|c|c|c|}
\hline & Model 1 & Model 2 & Model 3 & Model 4 \\
\hline & HR (99\% Cl) & HR (99\% Cl) & HR (99\% Cl) & HR $(99 \% \mathrm{Cl})$ \\
\hline \multicolumn{5}{|c|}{ Provider delay (weeks) } \\
\hline $\begin{array}{l}4 \\
20 \\
40 \\
60\end{array}$ & 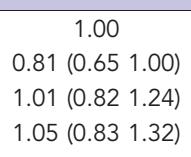 & $\begin{array}{c}1.00 \\
0.92(0.741 .15) \\
1.12(0.901 .38) \\
1.20(0.941 .52)\end{array}$ & $\begin{array}{c}1.00 \\
0.94(0.741 .19) \\
1.10(0.881 .38) \\
1.17(0.911 .49)\end{array}$ & 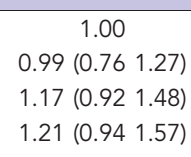 \\
\hline Age & & 1.04 (1.03 1.05) & $1.04(1.031 .05)$ & 1.04 (1.03 1.04) \\
\hline \multicolumn{5}{|l|}{ Gender } \\
\hline $\begin{array}{l}\text { Male } \\
\text { Female }\end{array}$ & & $\begin{array}{c}1.27(1.041 .56) \\
1.00\end{array}$ & $\begin{array}{c}1.26(1.021 .55) \\
1.00\end{array}$ & $\begin{array}{c}1.28(1.041 .58) \\
1.00\end{array}$ \\
\hline \multicolumn{5}{|l|}{ Smoking status } \\
\hline $\begin{array}{l}\text { Non-smoker } \\
\text { Current smoker } \\
\text { Ex-smoker } \\
\text { Not known }\end{array}$ & & $\begin{array}{c}1.00 \\
1.25(0.931 .68) \\
1.17(0.901 .52) \\
1.20(0.931 .53)\end{array}$ & $\begin{array}{c}1.00 \\
1.27(0.941 .72) \\
1.15(0.881 .50) \\
1.18(0.921 .52)\end{array}$ & 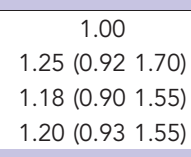 \\
\hline \multicolumn{5}{|c|}{ Carstairs deprivation quintile } \\
\hline $\begin{array}{l}1 \text { (least) } \\
2 \\
3 \\
4 \\
5 \text { (most) }\end{array}$ & & $\begin{array}{c}1.00 \\
0.96(0.721 .26) \\
1.36(1.031 .79) \\
1.28(0.951 .74) \\
1.30(0.851 .98)\end{array}$ & $\begin{array}{c}1.00 \\
0.98(0.741 .30) \\
1.37(1.041 .82) \\
1.31(0.961 .78) \\
1.32(0.862 .01)\end{array}$ & 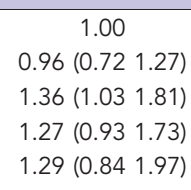 \\
\hline \multicolumn{5}{|c|}{ Place of presentation } \\
\hline $\begin{array}{l}\text { GP surgery } \\
\text { GP home visit } \\
\text { GP out of hours visit } \\
\text { Others } \\
\text { Unknown }\end{array}$ & & $\begin{array}{c}1.00 \\
1.19(0.891 .60) \\
0.91(0.551 .50) \\
1.18(0.652 .14) \\
1.17(0.681 .99)\end{array}$ & $\begin{array}{c}1.00 \\
1.20(0.891 .62) \\
0.92(0.551 .53) \\
1.18(0.642 .17) \\
1.09(0.611 .94)\end{array}$ & 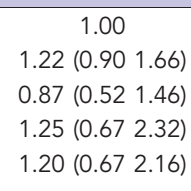 \\
\hline Charlson index & & $1.14(1.091 .18)$ & $1.13(1.081 .18)$ & $1.13(1.081 .18)$ \\
\hline \multicolumn{5}{|l|}{ Grade } \\
\hline $\begin{array}{l}\text { Grade I } \\
\text { Grade II } \\
\text { Grade III/IV } \\
\text { Ungradeable } \\
\text { Emergency admission }\end{array}$ & & & $\begin{array}{c}1.00 \\
1.21(0.761 .93) \\
1.84(1.113 .02) \\
1.58(0.962 .61) \\
1.00(0.781 .29)\end{array}$ & 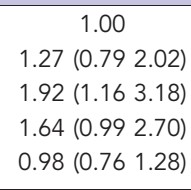 \\
\hline \multicolumn{5}{|l|}{ Symptoms and signs } \\
\hline $\begin{array}{l}\text { Constipation } \\
\text { Rectal bleeding } \\
\text { Abdominal pain } \\
\text { Anorexia } \\
\text { Weight loss } \\
\text { Abdominal mass }\end{array}$ & & & & 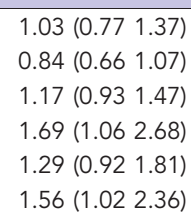 \\
\hline
\end{tabular}

since it is an intrinsic biological feature of the tumour less likely to be affected by provider delay. Symptoms and signs are complex, but, like emergency admission and place of presentation, are more likely to be markers of disease progression than intermediate variables. Hence, adjustment for grade, symptoms and signs, emergency admissions and place of presentation was performed since they may be markers for the more biologically aggressive tumours believed to produce 'waiting time paradox' of poorest outcome for those with shortest delays (Neal, 2009).
Context with other literature. In 2011, a Danish group addressed several methodological weaknesses in earlier work by analysing diagnostic delay in CRC as both a categorical and continuous variable using RCSs. (Tørring et al, 2011). They analysed patients with alarm symptoms separately from those with vague symptoms. Patients with vague symptoms did not have better survival, causing the authors to dispute the usual interpretation of the waiting time paradox (i.e, the most biologically aggressive tumours are diagnosed most quickly) since in this case, patients with vague 


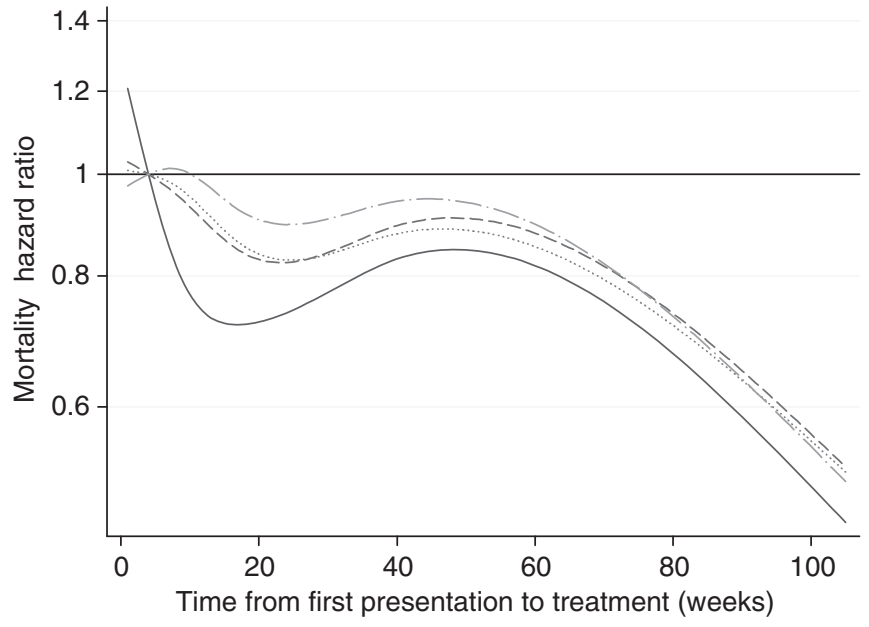

Figure 3. Spline curve of Cox proportional hazards regression of provider delay (weeks) on hazard ratio for mortality. Model 1 (solid line): unadjusted model with four knots (provider delay of 4 weeks used as reference). Model 2 (dashed line): adjusted for place of presentation, patient age, patient gender, smoking status, Carstairs deprivation quintile and Charlson index. Model 3 (dotted line): further adjusted for tumour grade and type of admission. Model 4 (long dash and dotted line): further adjusted for symptoms and signs of constipation, rectal bleeding, abdominal pain, anorexia, weight loss and abdominal mass.

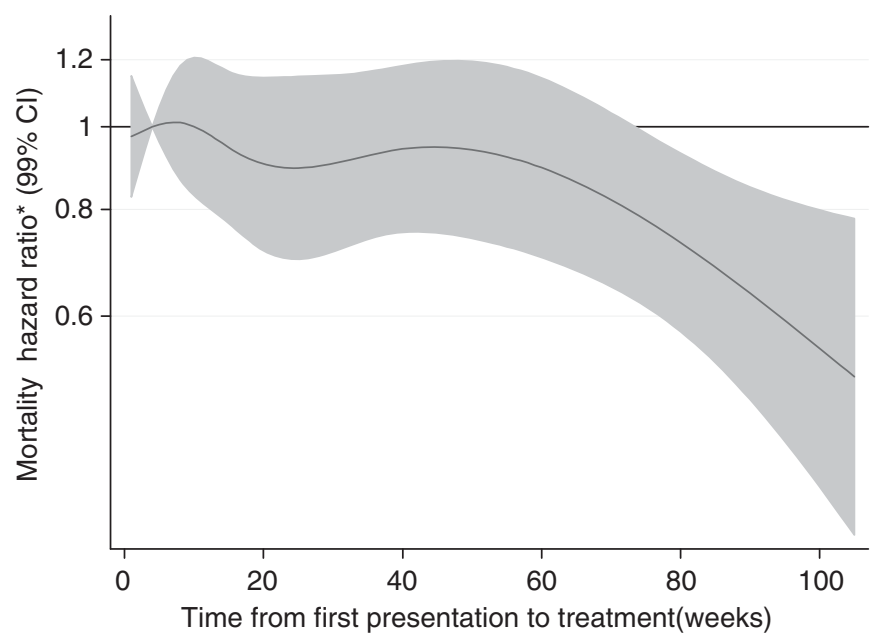

Figure 4. Spline curve of Cox proportional hazards model of provider delay (weeks) on hazard ratio (shaded area are $99 \% \mathrm{Cl}$ ) for mortality after multi-adjustment for potential confounders. Reference category is 4 weeks delay. Model adjusted for age, gender, smoking status, Carstairs deprivation quintile, Charlson index, place of presentation, tumour grade, type of admission, and for symptoms and signs of constipation, rectal bleeding, abdominal pain, anorexia, weight loss and abdominal mass.

symptoms and signs would have better overall survival. Instead, they argued that the waiting time paradox is produced when doctors expedite investigation and treatment of patients with dramatic symptoms (i.e, those that have waited the longest to present) and consequently a poorer prognosis. In patients presenting with alarm symptoms, those with the shortest diagnostic intervals had the poorest prognosis with 3-year mortality dropping initially, but then climbing after 6 weeks, a $\mathrm{U}$-shaped curve. In contrast, for patients with vague symptoms, the risk of 3-year mortality climbed from day 1 to week 12, although the relationship was not statistically significant. The authors concluded that the diagnostic interval does matter, especially in patients without alarm symptoms. Our unadjusted mortality analysis produced a similar curve, but once we adjusted for several prognostic factors, not available to the Danish investigators, which may confound the relationship between provider delay, stage-atpresentation and mortality, the initial sharp downswing of the $U$ flattens out, as does the later upswing. This suggests that these factors that are linked to tumour biology are more influential than provider delays. The Danish investigators based their survival analysis on survival from date of diagnosis, rather than date of first presentation in primary care. For this reason we have also performed a sensitivity analysis, where we have analysed survival from date of treatment (or definitive diagnosis as recorded in the Scottish Cancer Registry if no treatment). This has not appreciably affected our results, interpretations or conclusions.

A further study by the same authors combined data from two Danish datasets and one UK dataset $(n=1243)$ finding a similar U-shaped association between mortality and diagnostic delay (Tørring et al, 2012). Their combined results again support the assertion that longer diagnostic intervals cause higher mortality in patients with CRC, but again without accounting for many important potential confounders (Tørring et al, 2012). Notably this paper included a cohort from the UK, where survival began to decline after $\sim 15$ weeks, the same approximate relationship observed in our unadjusted mortality analysis.

The current approach has incorporated the methodological recommendations of Tørring et al (2011), but the nature of our dataset has permitted a more complete and detailed adjustment for particular symptoms and signs at diagnosis. Employing this approach, we believe, our analysis is less at risk from confounding.

Conclusions and implications. Prolonged provider delays before assessment cause people who may have cancer, and their families, anxiety and worry. Anxiety may be heightened by the commonly held view that provider delays of even a few weeks can adversely affect outcomes. In this sample of people diagnosed with CRC between 1997 and 1998 longer provider delays did not lead to poorer survival. While long delays are obviously undesirable, the imposition of tight cancer waiting times targets could curtail intensive preparation for major surgery, meaning resources are not being used to support the best potential outcomes of treatment (Tønnesen et al, 2009). There is also the risk that such efforts divert research and resource from increasing public awareness of cancer systems and reducing patient delays, which are generally agreed to have greater impact on cancer outcomes (Simon et al, 2010). Currently, the NHS prioritises waiting time targets and they are measured by the government with adverse publicity if they are not achieved. In turn, publicity around targets may, inadvertently, increase anxiety experienced by patients and relatives by reinforcing the unjustified belief that even modest delays impact on survival. Whether the current emphasis on awareness and early diagnosis in the UK will have any appreciable impact on reducing premature mortality from CRC remains to be proven, especially when compared with the biology of the underlying cancer, delays might be less important to outcome than is commonly believed.

\section{ACKNOWLEDGEMENTS}

The study was funded by NHS Grampian Research Endowment Award 11/26, and a grant from The Colorectal Study Fund (a NHS Grampian Endowment fund). The study was approved on 24 May 2011 by the Privacy Advisory Committee of ISD Scotland. Following discussion with the North of Scotland Research Ethics Committee it was decided on 7 February 2011 that formal ethical 
approval was not required. Research and Development approval was granted from NHS Grampian on 14 June 2011. The University of Aberdeen acted as sponsor for the study.

\section{CONFLICT OF INTEREST}

The authors declare no conflict of interest.

\section{AUTHOR CONTRIBUTIONS}

PM, DHB, NCC and AJL designed the study, with input from NG, LDR, RR and LS. EAR prepared the study databases and performed the data analysis under the direction of PM, DHB, NCC and AJL, with assistance from NG, LS and RR. PM wrote the manuscript with comments on drafts from all contributors.

\section{REFERENCES}

Atkin WS, Edwards R, Kralj-Hans I, Wooldrage K, Hart AR, Northover JM, Parkin DM, Wardle J, Duffy SW, Cuzick J (2010) Once-only flexible sigmoidoscopy screening in prevention of CRC: a multicentre randomised controlled trial. Lancet 375: 1624-1633.

Brewster DH, Stockton D, Harvey J, Mackay M (2002) Reliability of cancer registration data in Scotland, 1997. Eur J Cancer 38: 414-417.

Brewster DH, Stockton DL (2008) Ascertainment of breast cancer by the Scottish Cancer Registry: an assessment based on comparison with five independent breast cancer trials databases. Breast 17: 106-108.

Charlson ME, Pompei P, Ales KL, MacKenzie CR (1987) A new method of classifying prognostic comorbidity in longitudinal studies: development and validation. J Chron Dis 40: 373-383.

Department of Health (2007) Cancer Reform Strategy. Department of Health: London, England.

Dupout WD (2008) Statistical Modelling for Biomedical Researchers. 2nd edn, Cambridge University Press: Cambridge, UK.

Harley K, Jones C (1996) Quality of Scottish Morbidity Record (SMR) date. Health Bull (Edinb) 54: 410-417.

Hess KR (1995) Graphical methods for assessing violations of the proportional hazards assumption in Cox regression. Stat Med 14: 1707-1723.

Hewitson P, Glasziou P, Irwig L, Towler B, Watson E (2007) Screening for CRC using the faecal occult blood test, Hemoccult. Cochrane Database Syst Rev 1: CD001216.

Information and Statistics Division (ISD) (2013) of the NHS in Scotland website: (accessed 7 January 2013). http://www.isdscotland.org/.

Iversen LH, Antonsen S, Laurberg S, Lautrup MD (2009) Therapeutic delay reduces survival of rectal cancer but not of colonic cancer. Br J Surg 96: 1183-1189.

Kendrick S (1997) The development of record linkage in Scotland: the responsive application of probability matching.. In In record linkage techniques-1997: Proceedings of an International Workshop and Exposition, Arlington, VA, March 20-21, 1997, Alvey W, Jamerson B (eds) pp 319-332. Federal Committee on Statistical Methodology, Office of Management and Budget: Washington DC, Available at http://www. fcsm.gov/working-papers/skendrick.pdf.

Kendrick S, Clarke J (1993) The Scottish record linkage system. Health Bull 51: 72-79.
Morris R, Carstairs V (1991) Which deprivation? a comparison of selected deprivation indexes. J Public Health Med 13: 318-326.

Neal R (2009) Do diagnostic delays in cancer matter? Br J Cancer 101: S9-S12.

Ramos R, Esteva M, Cabeza E, Campillo C, Llobera J, Aguiló A (2007) Relationship of diagnostic and therapeutic delay with survival in CRC: a review. Eur J Cancer 43: 2467-2478.

Ramos R, Esteva M, Cabeza E, Llobera J, Ruiz A (2008) Lack of association between diagnostic and therapeutic delay and stage of CRC. Eur J Cancer 44: 510-521.

Richards MA (2009) The national awareness and early diagnosis initiative in England: assembling the evidence. $\mathrm{Br} J$ Cancer 101: S1-S4.

Robertson R, Campbell NC, Smith S, Donnan PT, Sullivan F, Duffy R, Ritchie LD, Millar D, Cassidy J, Munro A (2004) Factors influencing time from presentation to treatment of colorectal and breast cancer in urban and rural areas. Br J Cancer 90: 1479-1485.

Scottish Intercollegiate Guideline Network (SIGN) (2003) 67 Management of CRC: a national clinical guideline. SIGN: Edinburgh, UK.

Simon AE, Waller J, Robb K, Wardle J (2010) Patient delay in presentation of possible cancer symptoms: the contribution of knowledge and attitudes in a population sample from the United Kingdom. Cancer Epidemiol Biomarkers Prev 19(9): 2272-2277.

Simunovic M, Rempel E, Thérault ME, Baxter NN, Virnig BA, Meropol NJ, Levine MN (2009) Influence of delays to nonemergent colon cancer surgery on operative mortality, disease-specific survival and overall survival. Can J Surg 52: E79-E86.

Terhaar sive Droste J, Oort FA, van der Hulst RWM, Coupé VMH, Craanen ME, Meijer GA, Morsink LM, Visser O, van Wanrooij LJ, Mulder CJJ (2010) Does delay in diagnosing CRC in symptomatic patients affect tumour stage and survival. A population-based observational study. BMC Cancer 10: 332.

The Scottish Government. Better Cancer Care, An Action Plan: The Scottish Government, Edinburgh, UK, 2008.

Tønnesen H, Nielsen PR, Lauritzen JB, Møller AM (2009) Smoking and alcohol intervention before surgery: evidence for best practice. $\mathrm{Br} J$ Anaesth 102: 297-306.

Tørring ML, Frydenberg M, Hamilton W, Hansen RP, Lautrupe MD, Vedsted P (2012) Diagnostic interval and mortality in CRC: U-shaped association demonstrated for three different datasets. J Clin Epidemiol 65: 669-678.

Tørring ML, Frydenberg M, Hansen RP, Olesen F, Hamilton W, Vested P (2011) Time to diagnosis and mortality in CRC: a cohort study in primary care. Br J Cancer 104: 934-940.

Wattercheril J, Kramer JR, Richardson P, Havemann BD, Green LK, Le A, El-Serag HB (2008) Lagtimes in diagnosis and treatment of CRC: determinants and association with cancer stage and survival. Aliment Pharmacol Ther 28: 1166-1174.

Weller D, Vested P, Rubin G, Walter FM, Emery J, Scott S, Campbell C, Andersen RS, Hamilton W, Olesen F, Rose P, Nafees S, van Rijswijk E, Hiom S, Mutch C, Beyer M, Neal RD. The Aarhus statement: improving design and reporting of studies on early cancer diagnosis. Br J Cancer (2012) 106: 1262-1267.

This work is published under the standard license to publish agreement. After 12 months the work will become freely available and the license terms will switch to a Creative Commons AttributionNonCommercial-Share Alike 3.0 Unported License.

Supplementary Information accompanies this paper on British Journal of Cancer website (http://www.nature.com/bjc) 